\title{
DÜBLIN
}

Technological University Dublin

ARROW@TU Dublin

\section{Theobromine and related methylxanthines as inhibitors of Primary Amine Oxidase}

\author{
Padraig Shanahan \\ Technological University Dublin, padraigshanahan@icloud.com \\ Jeffrey O’Sullivan \\ Trinity College Dublin, JOSULLI@tcd.ie \\ Keith Tipton \\ Trinity College Dublin, ktipton@tcd.ie
}

See next page for additional authors

Follow this and additional works at: https://arrow.tudublin.ie/schfsehart

Part of the Biochemistry, Biophysics, and Structural Biology Commons, Biology Commons, and the Biotechnology Commons

\section{Recommended Citation}

Henehan, G. et al. (2018) Theobromine and related methylxanthines as inhibitors of Primary Amine Oxidase, J Food Biochem. 2018;e12697.

This Article is brought to you for free and open access by the School of Food Science and Environmental Health at ARROW@TU Dublin. It has been accepted for inclusion in Articles by an authorized administrator of ARROW@TU

Dublin. For more information, please contact

arrow.admin@tudublin.ie, aisling.coyne@tudublin.ie, gerard.connolly@tudublin.ie.

Funder: Technological University Dublin

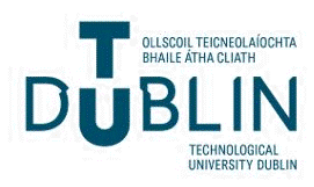




\section{Authors}

Padraig Shanahan, Jeffrey O'Sullivan, Keith Tipton, Gemma Kinsella, Barry Ryan, and Gary Henehan 


\section{Theobromine and related methylxanthines as inhibitors of Primary Amine Oxidase}

\section{Padraig Shanahan ${ }^{a}$, Jeff O'Sullivan ${ }^{b}$, Keith F Tipton', Gemma K Kinsella ${ }^{a}$, Barry J Ryan ${ }^{a}$, 3 Gary TM Henehan ${ }^{\mathrm{a}, \mathrm{d}}$}

4 a. Applied Enzymology Group, School of Food Science and Environmental Health, College of Science and Health, Dublin 5 Institute of Technology, Dublin 1, Ireland.

6 b. School of Dental Science, Trinity College Dublin, Dublin Ireland.

7 c. School of Biochemistry and Immunology, Trinity College Dublin, Dublin, Ireland.

d. Corresponding author

9

Padraig Shanahan, School of Food Science \& Environmental Health, Dublin Institute of Technology, Dublin 1, Ireland. Phone: +353-1-402 4408, Email: padraig.shanahan@dit.ie

Dr Jeff O'Sullivan, School of Dental Science, Trinity College Dublin 2. Ireland Phone: (Bio): +353 18961803 or (Dent): +353 16137385 Email: josulli@tcd.ie

Professor Keith F Tipton, School of Biochemistry and Immunology, Trinity College Dublin 2, Dublin, Ireland. Phone: + 353-1896 1802. Email: ktipton@tcd.ie,

Gemma Kinsella, School of Food Science \& Environmental Health, Dublin Institute of Technology, Dublin 1, Ireland. Phone +3531402 Email: gemma.kinsella@dit.ie

Dr Barry Ryan, School of Food Science \& Environmental Health, Dublin Institute of Technology, Dublin 1, Ireland. +353 1 402 4379, Email: barry.ryan@dit.ie

Dr Gary Henehan, School of Food Science \& Environmental Health, Dublin Institute of Technology, Dublin 1, Ireland. +353 870995 006, Email: gary.henehan@dit.ie

Acknowledgements: This work was supported by a Dublin Institute of Technology Fiosraigh Award to P. Shanahan. 
Methylxanthines are the most widely consumed drugs in the world and evidence of their health benefits has been growing in recent years. Primary Amine Oxidase (PrAO) has been recognised as a therapeutic target for amelioration of inflammatory, vascular and neurodegenerative diseases. Previous work in our laboratories showed that caffeine inhibited Bovine PrAO with a Ki of $1.0 \mathrm{mM}$ using benzylamine as substrate.

This study aimed to extend our previous work and explore the possibility that related methylxanthines might influence PrAO activity. While paraxanthine, theophylline and 7methylxanthine had little effect on PrAO, theobromine was a noncompetitive inhibitor with a Ki of $276 \pm 44 \mu \mathrm{M}$. The specific structural elements of methylxanthines that are required for inhibition allow us to suggest that their binding site on PrAO may be a target for therapeutics. The health benefits associated with dietary methylxanthine consumption could involve PrAO inhibition.

\section{Practical Applications}

Inhibition of PrAO by methylxanthines may be significant in conferring health benefits. The design of PrAO inhibitors based on the structural motifs identified in this study ( $\mathrm{N}$-methylation at specific locations) is indicated. Existing therapeutics based on a core xanthine structure can be evaluated for their effects on PrAO. Moreover, PrAO inhibition must be considered as a potential mediator of the beneficial health effects of some methylxanthines. If inhibition in human tissues is comparable to, or greater than, that found in these studies it points to an important role for these compounds in human health. 


\section{Introduction}

Caffeine, a methylxanthine, is among the most world's most widely consumed drugs. In recent years, evidence of health benefits associated with consumption of caffeine and other methylxanthines has been accumulating (Monteiro et al., 2016, Furman et al., 2017, Franco et al., 2013). These benefits range from lowering of inflammation to the prevention of neurodegenerative disease (Chrysant (2017), Kolahdouzan M and Hamadeh (2017). The effects of methylxanthines are primarily thought to be due to their binding to adenosine receptors (Monteiro et al., 2016, Salomone et al., 2017).

Primary Amine Oxidase (PrAO) is a copper-containing transmembrane glycoprotein that catalyses the following reaction:

$$
\mathrm{RCH}_{2} \mathrm{NH}_{2}+\mathrm{H}_{2} \mathrm{O}+\mathrm{O}_{2}-->\mathrm{RCHO}+\mathrm{NH}_{3}+\mathrm{H}_{2} \mathrm{O}_{2} \text {. }
$$

It contains a cytoplasmic domain, a transmembrane segment and an extracellular domain. In the vascular endothelium the extracellular domain may be cleaved off to give rise to a circulating form found in plasma. In some tissues, the membrane form acts as a Vascular Adhesion Protein (VAP-1) which is involved in the migration of leukocytes through the vascular endothelium at sites of inflammation (Pannecoeck et al., 2015). This extravasion process requires the amine oxidase activity catalyzed by PrAO to be intact (Noonan et al., 2013). Both the circulating plasma form and the membrane associated PrAO are active in amine oxidation and their endogenous substrates include methylamine and aminoacetone (see Lyles, 1996). These substrates are converted by PrAO to the toxic aldehydes formaldehyde and methylglyoxal respectively: such aldehydes can crosslink proteins in vivo giving rise to vascular damage (e.g. Unzeta et al., 2007). Finally, it has been shown that $\mathrm{H}_{2} \mathrm{O}_{2}$ generated by PrAO has a signalling role in the regulation of glucose uptake (see McDonald et al., 2007).

Raised levels of PrAO are seen in a number of disease states including diabetes, Alzheimer's disease and inflammation (Pannecoeck et al., 2015). The multiplicity of roles for PrAO in diverse processes has made it an important therapeutic target (O'Sullivan et al., 2004). Inhibitors of PrAO have been 
reported and its inhibition is known to have anti-inflammatory effects and to positively influence vascular health, neurodegenerative disease progress and lung fibrosis among other conditions (Horváth et al., 2017, Jarnicki et al., 2017).

Previous studies in these laboratories explored the inhibition of PrAO by amine compounds in food and drugs and showed that caffeine inhibited bovine PrAO with a Ki of $1.0 \mathrm{mM}$ (Olivieri et al., 2011, Olivieri and Tipton, 2011). A subsequent study (Che et al., 2012) showed that caffeine administration to rats inhibited PrAO activity in serum, brain and adipose tissue and raised the possibility that caffeine could be used in treating PrAO-associated disease. Trials assessing the impact of caffeine on PrAO activity in human subjects have been considered but have not yet been initiated (see https://clinicaltrials.gov/ct2/show/NCT02098785). The ability of dietary caffeine to inhibit PrAO in vivo is highly significant and points to the possibility that ingested food compounds might influence PrAO in humans in a similar manner to that seen in rat tissues (Che et al., 2012).

Recently, a study in human adipose tissue found that phenolic compounds in food blocked the downstream effects of $\mathrm{H}_{2} \mathrm{O}_{2}$ produced by $\operatorname{PrAO}$ albeit without directly inhibiting PrAO activity (Les et al., 2016). It is plausible that food components could be responsible for modulating the activity of PrAO and that such modulation might be a significant health benefit for people on a diet enriched in PrAO inhibiting components.

While our previous findings showed caffeine to be a PrAO inhibitor there is no information in the literature concerning PrAO inhibition by other methylxanthines. It was, therefore, of interest to examine whether caffeine-related compounds might contribute to modulation of PrAO activity. In this study we examined theobromine, paraxanthine, theophylline, 7-methylxanthine and their derivatives as modulators of bovine PrAO activity. Caffeine is found in the diet mainly in tea and coffee and as a component of energy drinks (Olivieri et al., 2011, Olivieri A and Tipton 2011). Theobromine and theophylline are ingested in tea and chocolate respectively (Monteiro et al., 
2016); paraxanthine is the major metabolite of caffeine in human tissues and 7-methylxanthine is the major paraxanthine metabolite (Furman et al., 2017).

\section{Materials and Methods}

Source of reagents: Bovine plasma PrAO was obtained from Langanbach Services Ltd, Bray, Ireland. Other chemicals used in this study were obtained from Sigma-Aldrich unless otherwise indicated.

Standard enzyme assay: PrAO activity was determined by following $\mathrm{H}_{2} \mathrm{O}_{2}$ production at $498 \mathrm{~nm}$, by the method of Holt and Palcic (2006), in the presence of $5.0 \mathrm{mM}$ benzylamine. The chromogenic solution for the detection of $\mathrm{H}_{2} \mathrm{O}_{2}$ contained $1 \mathrm{mM}$ vanillic acid, $0.5 \mathrm{mM}$ 4-aminoantipyrine and horseradish peroxidase $(4 \mathrm{U} / \mathrm{ml})$ in a 'physiological' HEPES buffer system (100 mM HEPES, $280 \mathrm{mM}$ $\mathrm{NaCl}, 10 \mathrm{mM} \mathrm{KCl}, 4 \mathrm{mM} \mathrm{CaCl} 2,2.8 \mathrm{mM} \mathrm{MgCl}$ ). The $\mathrm{pH}$ of the buffer was adjusted to 7.4 with $0.1 \mathrm{M}$ $\mathrm{NaOH}$. Assays were carried out in a reaction volume of $300 \mu \mathrm{l}$ in 96 -well microtitre plates, at $37^{\circ} \mathrm{C}$, using a SpectraMax 340PC plate reader (Molecular Devices, Inc. Sunnyvale, CA 94089-1136, USA). Control assays for the coupling system, in the presence of $10 \mu \mathrm{M} \mathrm{H}_{2} \mathrm{O}_{2}, 1 \mathrm{mU} / \mathrm{ml} \mathrm{HRP}$ but without PrAO, showed that none of the compounds affected the chromogenic detection system. Each compound was assayed in triplicate, at a final concentration of 0.5 or $1.0 \mathrm{mM}$.

Data analysis and curve fitting: Data for each methylxanthine tested as an inhibitor was obtained in three separate experiment each conducted in triplicate. Data are reported as mean +/- standard error of the mean. Dunnett's test was used to assess the statistical significance of differences between test and control data.

Kinetic data were directly fitted by non-linear regression to the Michaelis-Menten equation by Graph Pad Prism, version 5. Replots were fitted by linear regression. Double-reciprocal plots are shown for illustrative purposes only. 
121 The structures of the compounds tested in this study are shown in Figure 1 . The effect of caffeine, paraxanthine, theophylline, theobromine and 7-methylxanthine on PrAO at fixed concentrations of $500 \mu \mathrm{M}$ and 1.0mM was examined using the standard assay (Figure 2).

Of the five methylxanthines tested only caffeine and theobromine showed substantial inhibition of PrAO: surprisingly, the other compounds tested; theophylline, paraxanthine and 7-methylxanthine had relatively little effect.

Since caffeine is derived from xanthine we decided to test xanthine and related compounds as PrAO inhibitors. Figure 3 shows that neither xanthine, its metabolites hypoxanthine and uric acid, or imidazole had a significant inhibitory effect on PrAO activity at the concentrations used.

Since theobromine was the only compound showing activity comparable to that of caffeine its interaction with PrAO it was examined in greater detail. The pattern of inhibition with theobromine

This pattern of inhibition is similar to that seen with caffeine (Olivieri and Tipton K. (2011) although the Ki estimated was significantly lower for theobromine than for caffeine. 


\section{Discussion}

143 These findings, for the first time, identify theobromine as a modulator of bovine PrAO activity. This expands the range of compounds that can influence this important enzyme. Theobromine, which is a constituent of cocoa as well as a caffeine metabolite in humans, is a more effective inhibitor than caffeine. Theobromine has a longer plasma half-life than caffeine and is considered less active in the central nervous system and therefore is associated with less toxic side effects (Monteiro et al., 2017). The longer half-life of theobromine may mean its effects will be more prolonged than those of caffeine. It is also important to note that theobromine may be formed from caffeine breakdown in vivo (Oñatibia-Astibia et al., 2017).

In humans, the plasma concentration of theobromine has been reported to be as high as $63 \mu \mathrm{M}$ following the consumption of chocolate (Oñatibia-Astibia et al., 2017). The relationship between Ki and inhibitor concentration for a noncompetitive inhibitor is given by equation 1 :

$$
V \max a p p=\frac{V \max }{1+\frac{I}{K i}}
$$

Equation 1. Noncompetitive inhibition: The equation shows the relationship between maximum velocity, Vmax app (the apparent maximum velocity), in the presence of an inhibitor (I) and the maximum velocity in the absence of an inhibitor (Vmax). The term Ki is the inhibitor binding constant.

Using $63 \mu \mathrm{M}$ for [I] and $276 \mu \mathrm{M}$ for Ki we can calculate that Vmax app $=81 \%$ of Vmax. Thus, the maximum rate of $\operatorname{PrAO}$ in the presence of $63 \mu \mathrm{M}$ theobromine is reduced by approximately $20 \%$.

A study of plasma PrAO levels in human type 1 diabetes showed PrAO activity of $1049 \pm 294 \mathrm{mU} / \mathrm{L}$ versus an activity of $749 \pm 204 \mathrm{mU} / \mathrm{L}$ in control subjects (mean $\pm \mathrm{SD} ; \mathrm{p}<0.00001$ ) (see Januszewski et al., 2014). Thus, a difference of roughly $30 \%$ in PrAO activity correlated with renal dysfunction and vascular inflammation. A similar level of PrAO elevation was observed in hypertensive heart disease Marinho et al, 2010). Clearly, relatively modest increases in the level of this enzyme correlate with 
disease progression. In this context the level of inhibition observed in these studies is potentially significant.

The net effect of methylxanthines on PrAO activity may be complex and difficult to determine with accuracy since these compounds may derive directly from various components of the diet or arise as metabolites of caffeine. Assessing the combined effect of such compounds will require animal or preferably human trials. It is also worth noting that, in recent years, theobromine supplements have become widely available online as powders, capsules and pills for treatment of weight loss, blood pressure and cancer, among other conditions.

Structure activity relationships: Of particular importance was the observation that none of the methylxanthines besides caffeine and theobromine showed significant inhibition. This allowed us to identify structural features necessary for inhibition. Thus, 7-methylxanthine, a caffeine derivative lacking a methyl group at position 3, shows little inhibition. Similarly, theophylline, lacking the methyl group at position 7, is relatively ineffective as an inhibitor. It is clear that methylation of positions 3 and 7 on xanthine are necessary for inhibition. The lack of significant inhibition by these closely related compounds suggests that other elements of the xanthine structure contribute little to inhibitor binding. The lower Ki for theobromine relative to caffeine may be due to the formation of hydrogen bonds between the nitrogen in position 1 and amino acid side chains on PrAO. Imidazole was reported to be an inhibitor of PrAO at high concentrations (Elovaara et al., 2016) but at the highest level used herein (1.0mM) showed only mild inhibition (Figure 3 ).

Methylxanthine binding site: The pattern of inhibition is noncompetitive, implying that theobromine does not directly block substrate binding but still affects substrate turnover. This pattern is normally interpreted as the binding of inhibitor to a site other than the active site (Figure 5). Thus, the inhibitor may bind to both free enzyme and the enzyme substrate complex. However, the ping-pong mechanism of PrAO-catalysed amine oxidation means that ligands may bind to both oxidized and reduced forms of this enzyme yielding complex kinetic plots (see Holt et al., 2008). Noncompetitive 
inhibition might be expected if the methylxanthines bind within the substrate entrance channel of either oxidised or reduced forms of PrAO. A similar noncompetitive pattern of inhibition was observed with caffeine when benzylamine was the substrate although a mixed pattern of inhibition was seen when methylamine was the substrate (Olivieri and Tipton, 2011).

An imidazoline binding site on PrAO has been indicated in previous studies (Holt et al., 2008) and two imidazole binding sites have been identified on a crystal structure of human PrAO (Elovaara et al., 2011). The crystal structure showed imidazole bound to the topaquinone (TPQ) cofactor of both the oxidised and reduced forms of PrAO. It is possible that one of these sites might bind the methylxanthines of this study. Theobromine and caffeine presumably interact via hydrogen bond formation with residues of PrAO. Comparison with the other structures considered herein shows that inhibition is quite specific requiring the particular pattern of $\mathrm{N}$-methylation only found in caffeine and theobromine.

The well-known positive effects of caffeine and theobromine on vascular health, inflammation and neurodegenerative disease have been variously attributed to binding at adenosine receptors, phosphodiesterase inhibition, binding to GABA receptors or calcium regulation (Monteiro et al., 2016). Inhibition of PrAO has not been considered as significant in this process; however, the benefits ascribed to methylxanthines mirror those associated with PrAO inhibition. It is conceivable that modulation of PrAO activity by ingested methylxanthines and their metabolites might contribute to lowering PrAO activity in vivo. This in turn might account for the known dietary advantage associated with consumption of compounds in this class.

A great deal of effort has been directed towards the development of specific inhibitors of PrAO but efforts have been hampered by a lack of selectivity or because inhibitors contain highly reactive structural elements (see O'Rourke et al., 2008). It is possible that the caffeine/theobromine binding 
site identified here might offer an attractive target for PrAO inhibitor design since it can inhibit activity without affecting substrate affinity: a noncompetitive inhibitor, unlike a competitive inhibitor, will not be affected by fluctuations in the physiological concentration of substrates available to PrAO.

It is worth noting that caffeine derivatives have been explored previously in the treatment of neurodegenerative disease (Petzer and Petzer 2015, Pohanka 2015). For example, substitution at position 8 in caffeine to give 8-chlorostyrylcaffeine, produces a powerful reversible inhibitor of monoamine oxidase B (Binda et al, 2006). Likewise, substitutions on the nitrogen atom at position 1 of theobromine gives rise to the anti-inflammatory lisofylline and the antihistamine pentoxifylline (Pascal et al, 1985). Di-substituted derivatives such as the 3, 8 substituted compounds bamiphylline, naxifylline and rolofylline, with increased solubility, have also been investigated as cardioprotective drugs (Szentmiklósi et al, 2011). The effects of many of these drugs on MAO and PrAO have not been assessed although there is evidence that the inhibition of both enzymes may be beneficial in the management of neurodegenerative diseases, in combatting oxidative stress (Liu et al, 2010) and in the treatment of obesity (Carpéné et al, 2007). Thus, theobromine may provide a useful skeleton for the development of more powerful drugs and multi-target directed ligands. These findings provide a strong impetus to extend these studies to human tissues.

\section{Conflict of Interest}

On behalf of all authors, the corresponding author states that there is no conflict of interest. 
Binda C, Hubálek F, Li M, Castagnoli N, Edmondson DE \& Mattevi A. (2006) Structure of the human mitochondrial monoamine oxidase B: new chemical implications for neuroprotectant drug design. Neurology, 67(Suppl 2): S5-7.

Carpéné C, Iffiú-Soltesz Z, Bour S, Prévot D, Valet P. (2007) Reduction of fat deposition by combined inhibition of monoamine oxidases and semicarbazide-sensitive amine oxidases in obese Zucker rats. Pharmacol Res., 56, 522-530.

Che B, Wang L, Zhang Z, Zhang Y, Deng Y. (2012) Distribution and accumulation of caffeine in rat tissues and its inhibition on semicarbazide-sensitive amine oxidase. Neurotoxicology, 33, 1248-53.

Chrysant SG. (2017) The impact of coffee consumption on blood pressure, cardiovascular disease and diabetes mellitus. Expert Rev Cardiovasc Ther., 15, 151-156.

Elovaara H, Kidron H, Parkash V, Nymalm Y, Bligt E, Ollikka P, Smith DJ, Pihlavisto M, Salmi M, Jalkanen S, Salminen TA. (2011) Identification of two imidazole binding sites and key residues for substrate specificity in human primary amine oxidase AOC3. Biochemistry. 50(24):5507-20. Activity. PLoS One, 11, e0166935. and Chocolate. Nutrients, 5, 4159-4173. MH, Douchet I, Daburon S, Moreau JF, Nolan GP, Blanco P, Déchanet-Merville J, Dekker CL, Jojic V, 

older individuals into two extreme clinical and immunological states. Nat Med., 23,174-184.

259

Holt A, Smith DJ, Cendron L, Zanotti G, Rigo A, Di Paolo ML. (2008) Multiple binding sites for substrates and modulators of semicarbazide-sensitive amine oxidases: kinetic consequences. Mol Pharmacol., 73, 525-38.

Holt A, Palcic MM. (2006) A peroxidase-coupled continuous absorbance plate-reader assay for flavin monoamine oxidases, copper-containing amine oxidases and related enzymes. Nat Protoc., 1, 2498505.

Horváth Á, Menghis A, Botz B, Borbély É, Kemény Á, Tékus V, Csepregi JZ, Mócsai A, Juhász T, Zákány R, Bogdán D, Mátyus P, Keeble J, Pintér E, Helyes Z. (2017) Analgesic and Anti-Inflammatory Effects of the Novel Semicarbazide-Sensitive Amine-Oxidase Inhibitor SzV-1287 in Chronic Arthritis Models of the Mouse. Sci Rep., 7:39863.

Januszewski AS, Mason N, Karschimkus CS, Rowley KG, Best JD, O'Neal DN, Jenkins AJ. (2014) Plasma semicarbazide-sensitive amine oxidase activity in type 1 diabetes is related to vascular and renal function but not to glycaemia. Diab Vasc Dis Res. (4):262-269.

Jarnicki AG, Schilter H, Liu G, Wheeldon K, Essilfie AT, Foot JS, Yow TT, Jarolimek W, Hansbro PM. (2016) The inhibitor of semicarbazide-sensitive amine oxidase, PXS-4728A, ameliorates key features of chronic obstructive pulmonary disease in a mouse model. Br J Pharmacol., 173, 3161-3175.

Kolahdouzan M, Hamadeh MJ. (2017) The neuroprotective effects of caffeine in neurodegenerative diseases. CNS Neurosci Ther., 23, 272-290.

Les F, Deleruyelle S, Cassagnes LE, Boutin JA, Balogh B, Arbones-Mainar JM, Biron S, Marceau P, Richard D, Nepveu F, Mauriège P, Carpéné C. (2016 ) Piceatannol and resveratrol share inhibitory 
effects on hydrogen peroxide release, monoamine oxidase and lipogenic activities in adipose tissue, but differ in their antilipolytic properties. Chem Biol Interact., 258,115-25.

Liu YH, Wu WC, Lu YL, Lai YJ, Hou WC. (2010) Antioxidant and Amine Oxidase Inhibitory Activities of Hydroxyurea. Biosci. Biotechnol. Biochem., 74,1256-1260.

Lyles GA. (1996) Mammalian plasma and tissue-bound semicarbazide-sensitive amine oxidases: biochemical, pharmacological and toxicological aspects. Int J Biochem Cell Biol. 28:259-74.

Marinho C, Arduíno D, Falcão LM, Bicho M. (2010) Alterations in plasma semicarbazide-sensitive amine oxidase activity in hypertensive heart disease with left ventricular systolic dysfunction. 29 (1): 37-47.

McDonald A, Tipton K, O'Sullivan J, Olivieri A, Davey G, Coonan AM, Fu W. (2007) Modelling the roles of MAO and SSAO in glucose transport. J Neural Transm (Vienna)., 114, 783-6.

Monteiro JP, Alves MG, Oliveira PF, Silva BM. (2016) Structure-Bioactivity Relationships of Methylxanthines: Trying to Make Sense of All the Promises and the Drawbacks. Molecules, 21(8). pii: E974.

Noonan, T., Lukas, S., Peet, G. W., Pelletier, J., Panzenbeck, M., Hanidu, A., ... Modis, L. K. (2013). The oxidase activity of vascular adhesion protein-1 (VAP-1) is essential for function. American Journal of Clinical and Experimental Immunology, 2(2), 172-185.

Olivieri A, Rico D, Khiari Z, Henehan G, O'Sullivan J, Tipton K. (2011) From caffeine to fish waste: amine compounds present in food and drugs and their interactions with primary amine oxidase. J Neural Transm (Vienna), 118, 1079-89.

Olivieri A, Tipton K. (2011) Inhibition of bovine plasma semicarbazide-sensitive amine oxidase by caffeine. J Biochem Mol Toxicol., 25, 26-7. 

neurodegenerative diseases. Mol Nutr Food Res., 61, 6-10.

O'Rourke AM, Wang EY, Miller A, Podar EM, Scheyhing K, Huang L, Kessler C, Gao H, Ton-Nu HT, Macdonald MT, Jones DS, Linnik MD. (2008) Anti-inflammatory effects of LJP 1586 [Z-3-fluoro-2-(4methoxybenzyl) allylamine hydrochloride], an amine-based inhibitor of semicarbazide-sensitive amine oxidase activity. J Pharmacol Exp Ther., 324, 867-75.

O'Sullivan J, Unzeta M, Healy J, O'Sullivan MI, Davey G, Tipton KF. (2004) Semicarbazide-sensitive amine oxidases: enzymes with quite a lot to do. Neurotoxicology, 25, 303-15. (2015) Vascular adhesion protein-1: Role in human pathology and application as a biomarker. Crit Rev Clin Lab Sci., 52, 284-300.

Pascal JC, Beranger S, Pinhas H, Poizot A \& Désiles JP. (1985) New antihistaminic theophylline or theobromine derivatives. J. Med. Chem., 28, 647-652.

Petzer JP \& Petzer (2015) A Caffeine as a lead compound for the design of therapeutic agents for the treatment of Parkinson's disease. Curr. Med. Chem., 22, 975-988. of Coffee. Nutrients, 9, 85-95.

Pohanka M. (2015) The perspective of caffeine and caffeine derived compounds in therapy. Bratisl Lek Listy., 116, 520-530. Xanthine derivatives in the heart: blessed or cursed? Curr. Med. Chem., 18, 3695-3706. uncertainties. Curr Med Chem., (15), 1965-82. 

and its possible contribution to vascular damage in Alzheimer's disease. J Neural Transm (Vienna).

326 114(6):857-62.

327 
330 Figure 1: Structures of the methylxanthines considered in this study. These naturally-occurring compounds are all Nmethylated derivatives of xanthine.

Figure 2. Inhibition of PrAO activity by methylxanthines. Assays were carried out at $37^{\circ} \mathrm{C}$ and $\mathrm{pH} 7.4$ as described in materials and methods. The control was a standard assay of PrAO in the presence of $5.0 \mathrm{mM}$ benzylamine. The data shown are the mean $\pm \operatorname{SEM}(n=3)$. Asterisks denote a significant difference between treatments and the control $\left({ }^{*} P \leq 0.05 ;{ }^{* *} P \leq\right.$ $0.01 ; * * P \leq 0.001)$ using Dunnett's test.

Figure 3. Effect of xanthine and related compounds on PrAO activity. Assays were carried out at $37^{\circ} \mathrm{C}$ and $\mathrm{pH} 7.4$ as described in materials and methods. The control was a standard assay of PrAO in the presence of $5.0 \mathrm{mM}$ Benzylamine. All data are the mean \pm SEM of three separate determinations. Asterisks denote a significant difference between treatments and the control ( $\left.{ }^{*} \leq 0.05 ;{ }^{* * P} \leq 0.01{ }^{* * * P} \leq 0.001\right)$ using Dunnett's test.

Figure 4. (a) Pattern of inhibition of PrAO by theobromine. Assays were carried out as indicated in the methods section. Benzylamine concentration was varied between 1.0 and 5.0mM at various concentrations of caffeine: 0, 100, 200, 300, 400, $500,600 \mu \mathrm{M}$. The Lineweaver Burk plots are shown for illustrative purposes only: each data set was fitted to a rectangular hyperbola and Kmapp and Vmax estimated by non-linear regression with the aid of Graph Pad Prism 5.0. (b) A replot of slopes $\left(K m_{a p p} / V_{\text {max }}\right)$ for each line in Fig $4 a$ versus theobromine concentration was used to estimate Ki. A Ki of $276 \pm 44 \mu M$ mean $\pm \operatorname{SEM}(n=3)$ was estimated.

Figure 5. Noncompetitive inhibition mechanism. Where $E$ represents enzyme, $S$, the substrate, $P$ the product and I the inhibitor. The constant $K$ for substrate binding is unaffected by the binding of inhibitor. The inhibitor binding constant is denoted $K_{1}$. In this mode of inhibition the inhibitor binds equally to free enzyme and enzyme-substrate complex (ES) causing 
Figure 1

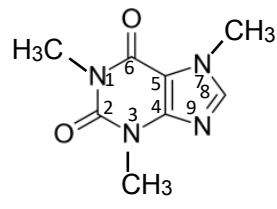

CAFFEINE

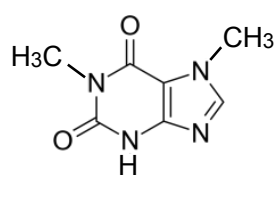

PARAXANTHINE

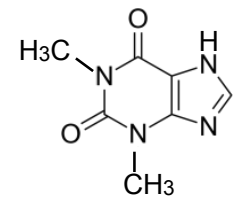

THEOPHYLLINE

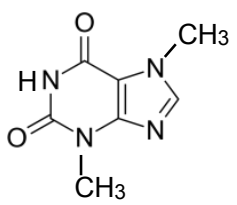

THEOBROMINE<smiles>Cn1cnc2[nH]c(=O)[nH]c(=O)c21</smiles>

7-METHYLXANTHINE 
Figure 2

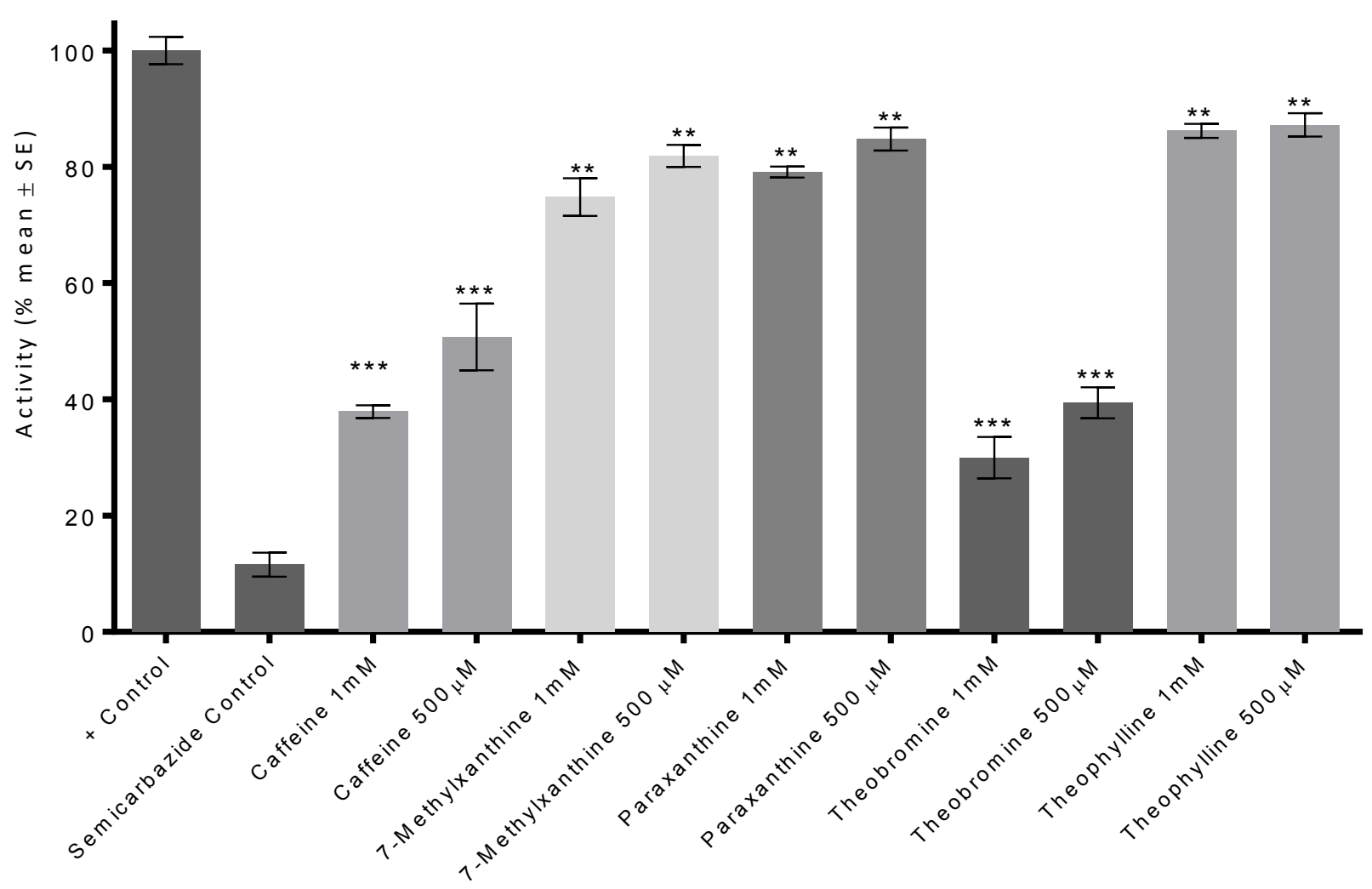


Figure 3

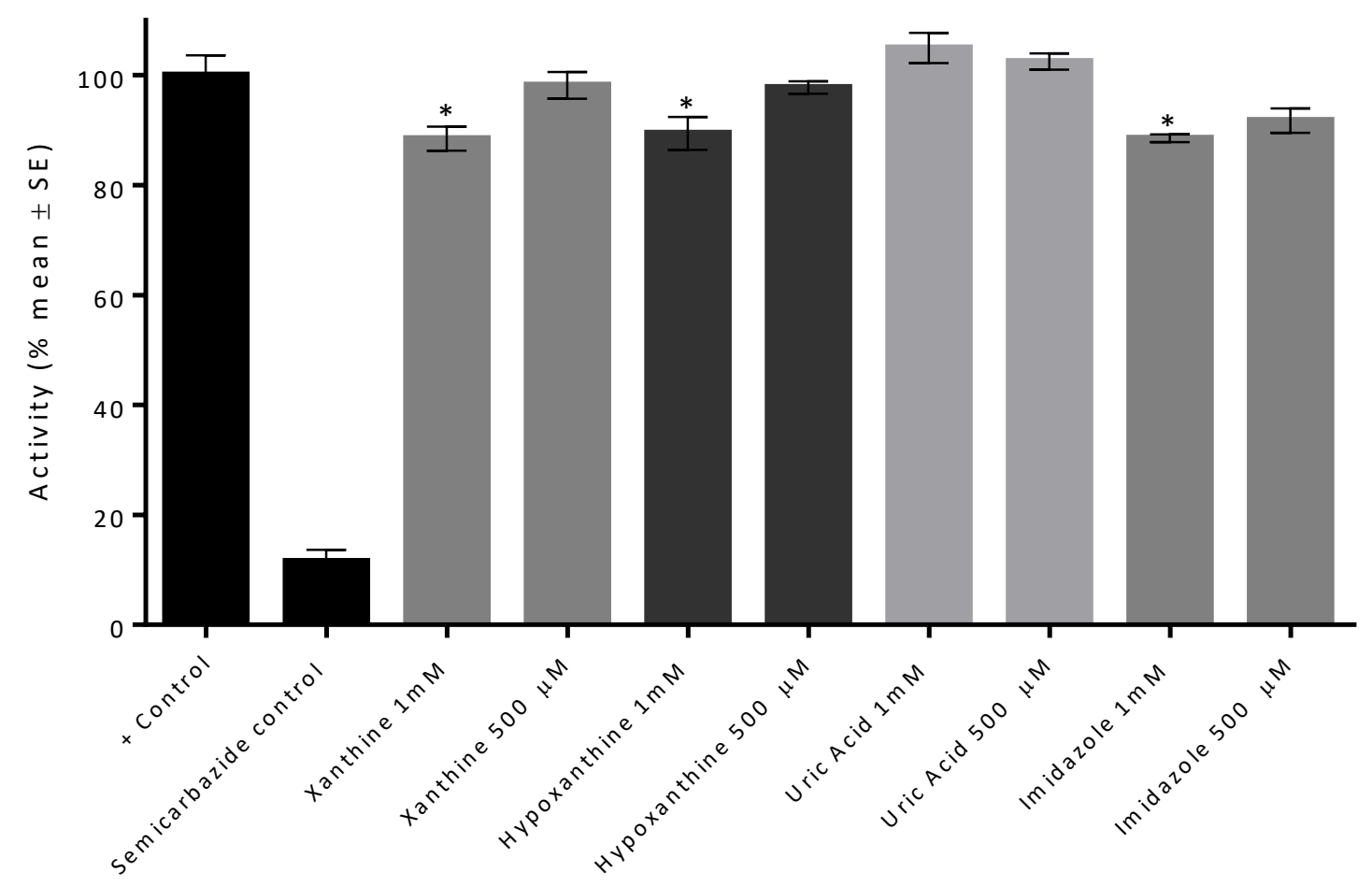


Figure 4a

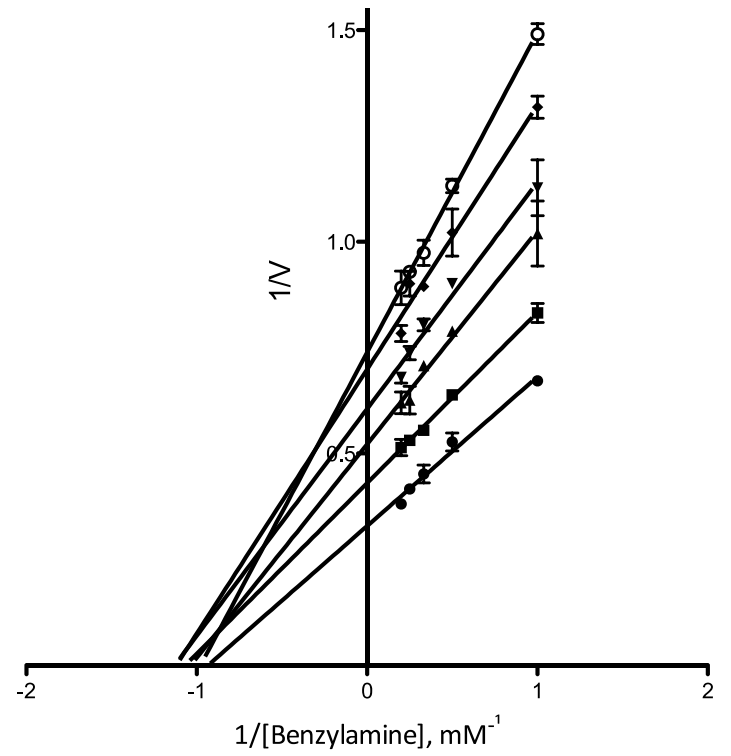

Figure $4 b$

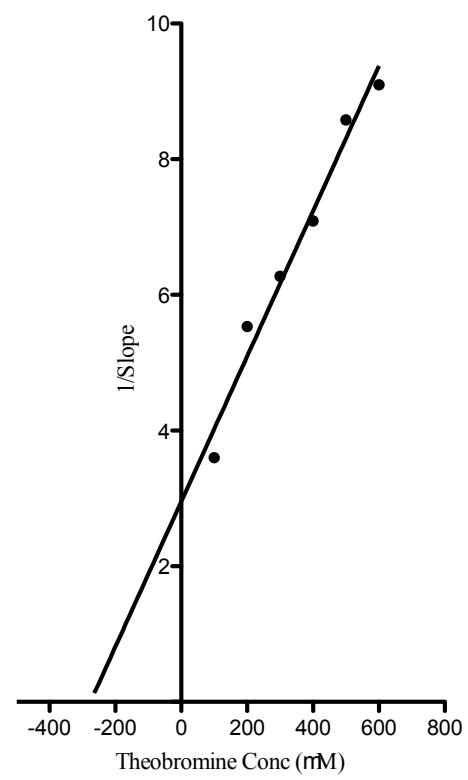


Figure 5

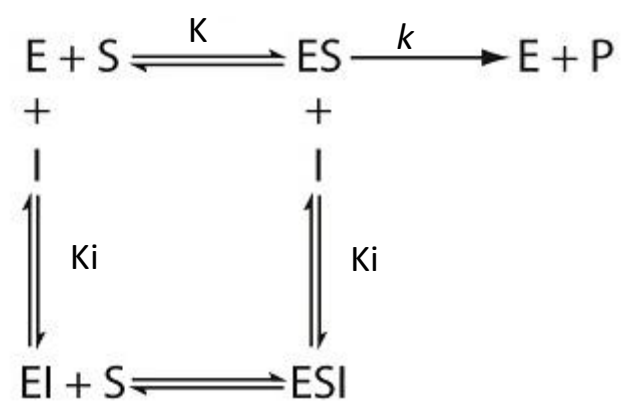

